\title{
Signal Averaged Electrocardiogram in Top Deficient Athletes
}

\author{
Japy Angelini Oliveira Fo , Bráulio Luna $\mathrm{F}^{\circ}$, Silvia Helena Covre, Edgar Lira F⿳, Marcelo Regazzini, José \\ Greco, Antônio Carlos Silva, Dirceu Vieira Santos Fo, Ângelo Amato Vincenzo de Paola
}

São Paulo, SP - Brazil

Eight cases of late potentials (LP) in signal averaged electrocardiogram (SAECG) are described in 75 (11\%) athletes who have no evidence of heart disease. These athletes were part of a consecutive series of 79 top deficient athletes. The cardiological assessment using electrocardiography, dynamic electrocardiography, vectorcardiography, echocardiography and treadmill testing showed absence of heart disease in all cases. Signs of athletic heart were found in 8 cases: one sign ( 4 cases), 2 signs ( 1 case), 3 signs ( 2 cases), 4 signs ( 1 case). The $11 \%$ prevalence of LP in this group of athletes is significant when compared with the $1.4 \%$ prevalence of LP in healthy individuals described in the literature $(\mathrm{p}<0.001)$. Follow-up of these 8 athletes during a period of approximately $22.5 \pm 2.8$ months failed to reveal cardiac events. Although the existence of a subgroup of athletes with particular features cannot be ruled out, the results show the low positive predictive value of the presence of LP in the SAECG in a population with a low prevalence of fatal cardiac events. This finding supports the validity of Bayes theorem.

SAECG has been used for the identification of patients at high risk for developing sustained ventricular tachycardia and/or sudden death. This test detects LP of low amplitude and a very high rate in the terminal portions of the QRS complex, related to the fragmented and delayed electrical activity of the ventricles ${ }^{1-3}$. The presence of LP would represent the electrophysiological substrate for the reentry phenomena, which accounts for the development of sustained ventricular tachycardia and some forms of nonsustained ventricular tachycardia ${ }^{4}$. After an acute myocardial infarction, LPs were reported in $70-90 \%$ of the patients with sustained and/or induced ventricular tachycardia, and in $7-15 \%$ of the patients without ventricular tachycardia; in healthy volunteers, the reported incidence of LP was $0-6 \%{ }^{5}$. Other uses of SAECG include the assessment of patients with syncope, ventricular tachycardia and dilated cardiomyopathy ${ }^{1,4-6}$.

Universidade Federal de São Paulo - Escola Paulista de Medicina Mailing address: Japy A. Oliveira Fo - Av. Brig. Faria Lima, 1893 - conj. 31-A 01451-001 - São Paulo, SP - Brazil
In the present study, we discuss SAECG tracings that indicate the existence of LP in 8 out of a consecutive series of 79 elite handicapped athletes who underwent noninvasive cardiological evaluation ${ }^{7}$.

\section{Report of the cases}

Seventy-nine consecutive cases of top deficient athletes (48 physically handicapped, 12 visually handicapped and 19 with cerebral palsy) from a variety of sport modalities, $27.8 \pm 6.7$ years of age, 59 of whom were men, were assessed. The protocol included physical examination, electrocardiography (ECG), 24-hour dynamic electrocardiography - Holter monitoring (HM), Doppler echocardiography (ECHO), vectorcardiogram (VCG), exercise testing (ET), SAECG and serologic testing for Chagas' disease (hemagglutination). The HM was performed in 6 cases and the VCG, in 6 cases. All patients had negative results in the serological tests.

The SAECG was performed with Predictor software, version 6.1, (Corazonix Corp. - USA), using 3 orthogonal leads $\mathrm{X}, \mathrm{Y}, \mathrm{Z}$, and a filter of $40 \mathrm{~Hz}$. Cases that showed at least one of the 3 following signs were defined as having LP: QRS duration $(\mathrm{QRSD})>114 \mathrm{~ms}$, duration of the low amplitude potentials ( $<40$ microvolt - LAS $)>38 \mathrm{~ms}$, and mean voltage of the last 40ms of the filtered QRS complex (RMS - 40) $<20$ microvolt $^{2}$.

Identification of the athletes and the individual results of the parameters obtained in the SAECG are shown in table I.

Case 1 - A 24-year-old asymptomatic male track and field athlete with cerebral palsy; ECG, sinus bradyarrhythmia, pattern of early repolarization, U Wave; VCG, biventricular overload; ET and ECHO, within the normal range; $\mathrm{HM}$, 4 ventricular extrasystoles (VE), 2 paired VE; the followup for 21 months failed to show cardiac events.

Case 2 - A 31-year-old physically handicapped male soccer player, with indefinite and sporadic palpitations and a mitral systolic murmur +; ECG, sinus bradycardia and pattern of early repolarization, U Wave; VCG, right anterior divisional block; ET within the normal range with paired and 


\begin{tabular}{|ccccc|}
\hline $\begin{array}{c}\text { Table I - Identification of the athletes and individual results of } \\
\text { the parameters of the signal averaged electrocardiography }\end{array}$ \\
\hline Identification & QRSD & LAS & RMS & $\mathrm{n}$ \\
& & & & \\
\hline 1 & 115.0 & 39.5 & 18.97 & 3 \\
2 & 112.0 & 52.0 & 16.23 & 2 \\
3 & 120.5 & 31.5 & 24.35 & 1 \\
4 & 119.5 & 35.0 & 17.01 & 2 \\
5 & 124.0 & 40.0 & 11.59 & 3 \\
6 & 116.0 & 46,0 & 13.07 & 3 \\
7 & 126.0 & 17.69 & 33.0 & 2 \\
8 & 105.0 & 45.5 & 17,31 & 2 \\
\hline
\end{tabular}

sporadic VE; ECHO within the normal range; HM, frequent VE, sinus bradyarrhythmia; the follow-up for 25 months failed to show cardiac events.

Case 3 - An 18-year-old physically handicapped male soccer player, who suffered from seizures until the age of 14 years (undergoing neurological therapy), showed a systolic mesocardial murmur +; ECG, early repolarization pattern, $U$ Wave; ET and ECHO within the normal range; HM, sinus arrhythmia and 3 supraventricular extrasystoles (SVE); the 17-month follow-up failed to show cardiac events.

Case 4 - A 23-year-old physically handicapped male soccer player, (undergoing neurological therapy for seizures), with indefinite complaints of sporadic dizziness, inconstant splitting of the second heart sound; ECG, pattern of early repolarization, U Wave; VCG, right inferior divisional block; ET, ECHO and HM, within the normal range; the 25month follow-up failed to show cardiac events.

Case 5 - A 33-year-old asymptomatic physically handicapped male pentathlete, showing a mitral systolic murmur + and a systolic click; ECG, sinus bradyarrhythmia, pattern of early repolarization, U Wave; VCG, right ventricular overload; ET and ECHO within the normal range; HM, 1 VE; the 24-month follow-up, failed to show cardiac events (fig. 1).

Case 6 - A 23-year-old visually handicapped male judoka, with nonanginal chest pain and a mesocardial systolic click; ECG, right inferior divisional block; ET and ECHO within the normal range; HM, sinus arrhythmia; 25month follow-up failed to show cardiac events.

Case 7 - A 23-year-old asymptomatic physically handicapped male swimmer; ECG, sinus bradyarrhythmia, pattern of early repolarization; ET and ECHO within the normal range; the 21-month follow-up failed to show cardiac events.

Case 8 - A 49-year-old asymptomatic physically handicapped male table tennis player, with a baseline
Signal average electrocardiogram in top deficient athletes

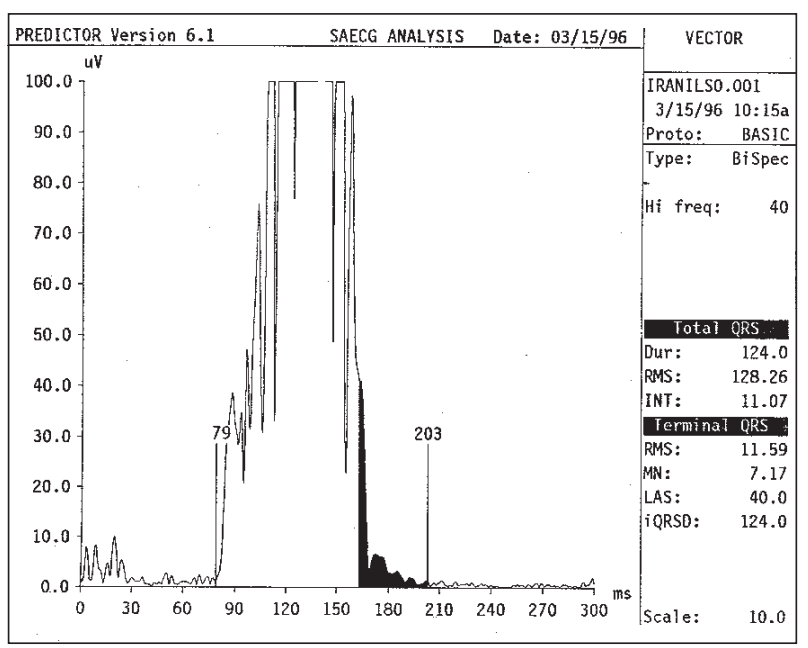

Fig. 1 - Case 5 - Signal averaged electrocardiography with late potentials $(\mathrm{QRSD}=$ $124 \mathrm{~ms}, \mathrm{LAS}=40 \mathrm{~ms}, \mathrm{RMS}=11.59$ microvolt $)$.

systolic murmur + and a mesocardial systolic click; ECG, U Wave; ET and ECHO within the normal range; the 22-month follow-up failed to show cardiac events.

\section{Discussion}

Rare cases of sudden death in athletes during competitions have occurred. In the subgroup of individuals 30 years of age or older, these events have been mainly attributed to coronary heart disease whereas in the group under 30 years of age, hypertrophic cardiomyopathy has been considered the main cause ${ }^{8}$. To analyze the usefulness of the SAECG in cases of coronary heart disease, syncope and dilated cardiomyopathy to stratify the risk of severe cardiac events, the presence of LP in top deficient athletes was studied. Of 79 athletes, 75 of whom had no indication of cardiovascular diseases, 8 (9.8\%) athletes with LP were noted ${ }^{1}$. Thus, the prevalence of LP was slightly higher than that found in healthy volunteers ${ }^{5}$.

The athletic heart is a condition characterized by clinical, radiological and electrocardiographic signs and exists in active athletes. It is the result of physiological adaptations to prolonged physical exercise ${ }^{7}$. Generally, the following findings are considered signs of athletic heart: systolic click, systolic murmur, presence of $3^{\text {rd }}$ and $4^{\text {th }}$ heart sounds, sinus bradycardia, sinus arrhythmia, incomplete right bundle branch block, ventricular overload, early repolarization juvenile pattern of the T wave, cavitary diameters and ventricular thickness above or within the upper normal limit ${ }^{7}$. All 8 athletes in our study showed signs of athletic heart: 1 sign ( 4 cases); 2 signs (1 case); 3 signs ( 2 cases); 4 signs ( 1 case $)^{7}$.

In all the 8 athletes, the absence of classical symptoms related to cardiac dysrhythmias, the normal results of TT and ECHO, the absence of significant arrhythmias at the DECG and the negative results of the serological tests for Chagas disease supported the hypothesis of the absence of heart disease in these cases. The series of 79 consecutive athletes showed the presence of coronary risk factors in 
$37 \%$ of the cases, with a potential risk in $15 \%$, a moderate risk in $3 \%$ and no risk in $70 \%{ }^{9}$.

Borbola and Denes ${ }^{10}$ conducted a literature review on the incidence of LP in healthy individuals and found 16 studies between 1981 and 1988, which included 513 individuals in control groups. The age ranged from 18 to 67 years, with means ranging between 29 and 37 years. The prevalence of LP ranged from 0 to $7 \%$ (mean, 1.4\%). In our case series, a prevalence of $9.8 \%$ in the athletes overall and of $11 \%$ among athletes with no evidence of heart diseases $(n=67)$ was reported. There was a significant difference between this figure of $11 \%$ and the figures reported in the literature $(1.4 \%)(\mathrm{p}<0,001 \%)$. Coto et al ${ }^{11}$ described a $6 \%$ prevalence of LP in 50 healthy individuals, out of which 38 were athletes and 12 exercised regularly. In our series, followup of the athletes after approximately 2 years failed to show any cardiac events. Although we cannot rule out the existence of a subgroup of athletes with special features, these results may be explained by the Bayes theorem, which shows the lower positive predictive value of diagnostic tests in a population with a low prevalence of a specific disease ${ }^{12}$. Thus, we emphasize again the significance of the clinical findings in the interpretation of subsidiary diagnostic tests.

\section{References}

1. Haten DM, Gus M, Halperin C. Aplicações clínicas do eletrocardiograma de alta resolução. Arq Bras Cardiol 1993; 60: 357-60.

2. El-Sherif N, Gomes JAC, Restivo M, Mehra R. Late potentials and arrhytmogenesis. PACE 1985; 8: 440-62.

3. Gruppi CJ, Barbosa SF, Moffa PJ. Síncope: possibilidades diagnósticas e avaliação. Arq Bras Cardiol 1991; 56: 73-7.

4. Maia IG, Alves PAG. O eletrocardiograma de alta resolução. In: Maia IG. Arritmias Cardíacas. Rio de Janeiro, SBC/DAEC, Sanoffi Winthrop, 1994.

5. Zipes DP. Genesis of cardiac arrhytmias electrophysiological considerations. In: Braunwald E. Heart Disease. Philadelphia: WB Saunders, 1997.

6. Kuchar DL, Thorburn CW, Sammel NL. Signal averaged electrocardiogram for evaluation of recurrent syncope. Am J Cardiol 1986; 58: 949-53.

7. Oliveira F. JA, Silva AC, Lira F. ${ }^{\circ}$ E, et al. Coração de atleta em desportistas deficientes de elite. Arq Bras Cardiol, 1997; 69: 385-8.
8. Ghorayeb N, Batlouni M, Dioguardi GS, et al. Problemas cardiovasculares em atletas. In: SOCESP. Cardiologia. São Paulo: Atheneu, 1996.

9. Oliveira F. ${ }^{\circ} \mathrm{JA}, \mathrm{Covre} \mathrm{SH}$, Salvetti XM, et al. Fatores de risco coronário em atletas deficientes de elite. Arq Bras Cardiol, 1997; 69(supl I): 89.

10. Borbola J \& Denes P. Late potentials in patients with sustained ventricular tachycardia. In: El-Sherif N, Turitto G (eds). High-Resolution Electrocardiography. Mount Kisco (NY): Futura, 1992: 495-520.

11. Coto H, Maldonado C, Palakurthy P, Flowers NC. Late potentials in normal subjects and in patients with ventricular tachycardia unrelated to myocardial infarction. Am J Cardiol 1985; 55: 384-90.

12. Bayes T. An essay toward solving a problem in the doctrine of chance. Philos Trans R Soc London 1763; 53:360. Apud: Epstein SE. Implications of probability analysis on the strategy used for non invasive detection of coronary heart disease. Am J Cardiol 1980; 46: 491. 